\title{
Was the 2011 Tohoku-Oki earthquake preceded by aseismic preslip? Examination of seafloor vertical deformation data near the epicenter
}

\author{
R. Hino $\cdot$ D. Inazu $\cdot$ Y. Ohta $\cdot$ Y. Ito $\cdot$ \\ S. Suzuki $\cdot$ T. Iinuma $\cdot$ Y. Osada $\cdot$ M. Kido $\cdot$ \\ H. Fujimoto $\cdot$ Y. Kaneda
}

Received: 2 July 2013/ Accepted: 23 November 2013/Published online: 30 November 2013

(C) The Author(s) 2013. This article is published with open access at Springerlink.com

\begin{abstract}
Ocean-bottom pressure records obtained near the epicenter of the 2011 Tohoku-Oki earthquake were examined to test whether the earthquake was preceded by substantial precursory crustal deformation. The seafloor data enabled us to search for small-scale preslip near the epicenter that would be difficult to identify from terrestrial geodetic data. After treating the data to reduce nontectonic fluctuations, we obtained a time series of seafloor vertical deformation in the epicentral region with a noise level of $2-4 \mathrm{~cm}$. No significant crustal deformation related to preslip was detected in the period of roughly a day before the mainshock, whereas postseismic deformation associated with the largest foreshock 2 days before the mainshock was apparent. From our quantitative estimate of the sensitivity of the seafloor network in detecting slip on the plate interface, we conclude that the Tohoku-Oki earthquake was not preceded by preslip with moment release greater than moment magnitude $(\mathrm{Mw}) 6.2$ in the vicinity of the hypocenter or greater than $\mathrm{Mw} 6.0$ along the subduction interface near the trench.
\end{abstract}

R. Hino $(\bowtie) \cdot$ T. Iinuma $\cdot$ Y. Osada $\cdot$ M. Kido $\cdot$ H. Fujimoto International Research Institute of Disaster Science, Tohoku University, Sendai, Japan

e-mail: hino@aob.gp.tohoku.ac.jp

D. Inazu

National Research Institute for Earth Science and Disaster

Prevention, Yokohama, Japan

Y. Ohta $\cdot$ Y. Ito $\cdot$ S. Suzuki

Graduate School of Science, Tohoku University, Sendai, Japan

Y. Kaneda

Japan Agency for Marine-Earth Science and Technology,

Yokohama, Japan
Keywords Precursory slip · Interplate megathrust earthquake $\cdot$ Seafloor vertical deformation .

Ocean-bottom pressure monitoring

\section{Introduction}

Temporal changes in aseismic crustal deformation precursory to the occurrence of earthquakes have been investigated for many large earthquakes. If they can be detected successfully, changes in deformation rates may facilitate warnings of imminent earthquakes. One possible cause of pre-earthquake deformation rate changes is a quasi-static aseismic slip associated with a transitional process before a fault rupture reaches high-speed seismic slip (e.g. Scholz 2002). Observations of preseismic deformation, therefore, are also important for understanding earthquake generation. However, a comprehensive review by Roeloffs (2006) found few credible published accounts of preseismic crustal deformation events. In subduction environments, it appears that deformation events can be categorized into two groups according to their lead time before the mainshock: those with a lead time of less than about a month and those with a lead time longer than that. The former group includes a deformation event 1 day before the 1944 Tonankai earthquake, identified by leveling, and an event 3 days before the 1946 Nankai earthquake, detected by water-level changes in wells. Linde and Sacks (2002) attributed these events to aseismic slip along the downdip side of the mainshock rupture areas. These two aseismic precursory slip events released seismic moment equivalent to earthquakes of moment magnitude (Mw) 7.8 and 7.9, respectively, amounting to approximately one-third of the moment released by the corresponding mainshocks. However, no clear preseismic deformation event has been 
identified in high-quality geodetic data from dense continuous GPS (cGPS) observation networks installed in the late 20th century. Melbourne and Webb (2002) reported precursory transient slip prior to an Mw 7.6 aftershock of the 2001 Peru earthquake ( $M w ~ 8.4)$, although their result was based on a displacement time series from a single cGPS observation site. Before the 2003 Tokachi-Oki earthquake, no anomalous deformations exceeding background noise level were observed in cGPS data sampled at 1 or $30 \mathrm{~s}$ intervals. Roeloffs (2006) estimated the maximum size of aseismic slip events not detectable in cGPS data to be $\sim \mathrm{M} 7$, less than $1 \%$ of the mainshock moment.

Since the 11 March 2011 Tohoku-Oki earthquake (Mw 9.0), extensive research has been done to detect and characterize precursory changes in the crustal deformation rate. Nishimura (2012) used dense cGPS network data to estimate the spatial distribution of the slip deficit along the top of the subducting Pacific slab and showed that the interplate coupling was significantly decreased in 2008-2010 compared to 1997-1999. Ozawa et al. (2012) found that the rate of moment release by aseismic slip increased in 2005, 6 years before the earthquake. This could be an example of a precursory crustal deformation events with a long lead time. In onshore tilt data, Hirose (2011) found no shortterm changes in deformation rate preceding the TohokuOki earthquake and concluded that no short-term preslip larger than Mw 6.2 occurred on the deeper extension of the mainshock rupture zone. However, the ability to detect offshore slip from the tilt data is relatively poor, and aseismic slip smaller than $\mathrm{Mw} 7.3$ could not have been detected even if it occurred around the epicenter or on the updip side of the rupture zone.

The focal area of the Tohoku-Oki earthquake was well instrumented with seafloor geodetic instruments. The observations of huge coseismic displacements (Sato et al. 2011; Kido et al. 2011; Ito et al. 2011) gave strong constraints on the slip distribution of the mainshock rupture (Iinuma et al. 2012; Ozawa et al. 2012). Eight ocean bottom pressure recorders (OBPRs) deployed near the epicenter of the Tohoku-Oki earthquake (Fig. 1, Table 1) since 2010 provided continuous time series data of seafloor vertical displacement. This paper presents an analysis of these continuous OBPR data to seek possible rate changes in preseismic crustal deformation.

In assessing precursory deformation, we have to take account of foreshock activity (Kato et al. 2012) and its associated aseismic slip. On 9 March the largest foreshock, an Mw 7.3 event, occurred about $20 \mathrm{~km}$ northeast of the mainshock hypocenter. This was followed by a number of smaller interplate earthquakes, including the second-largest foreshock (Mw 6.6) $18 \mathrm{~h}$ later. Coseismic and postseismic deformation from the largest foreshocks were clearly observed by cGPS and OBPRs (Ohta et al. 2012). Ito et al. (2013) analyzed OBPR data and reported
Fig. 1 Map of the hypocentral region of the 2011 Tohoku-Oki earthquake. Crosses indicate the locations of OBPRs. White, gray, and black stars represent epicenters of the mainshock, the largest foreshock, and the second largest foreshock, respectively. Solid dots are epicenters of foreshocks that occurred between the largest foreshock and the mainshock. Contours show the depth to the Pacific plate (10 km interval). Pink shading is the area with $>30$ m coseismic slip in the mainshock (Iinuma et al. 2012), green shading is the area with $>1 \mathrm{~m}$ coseismic slip in the largest foreshock, and blue shading is the area with $>0.3 \mathrm{~m}$ afterslip following the largest foreshock (Ohta et al. 2012)

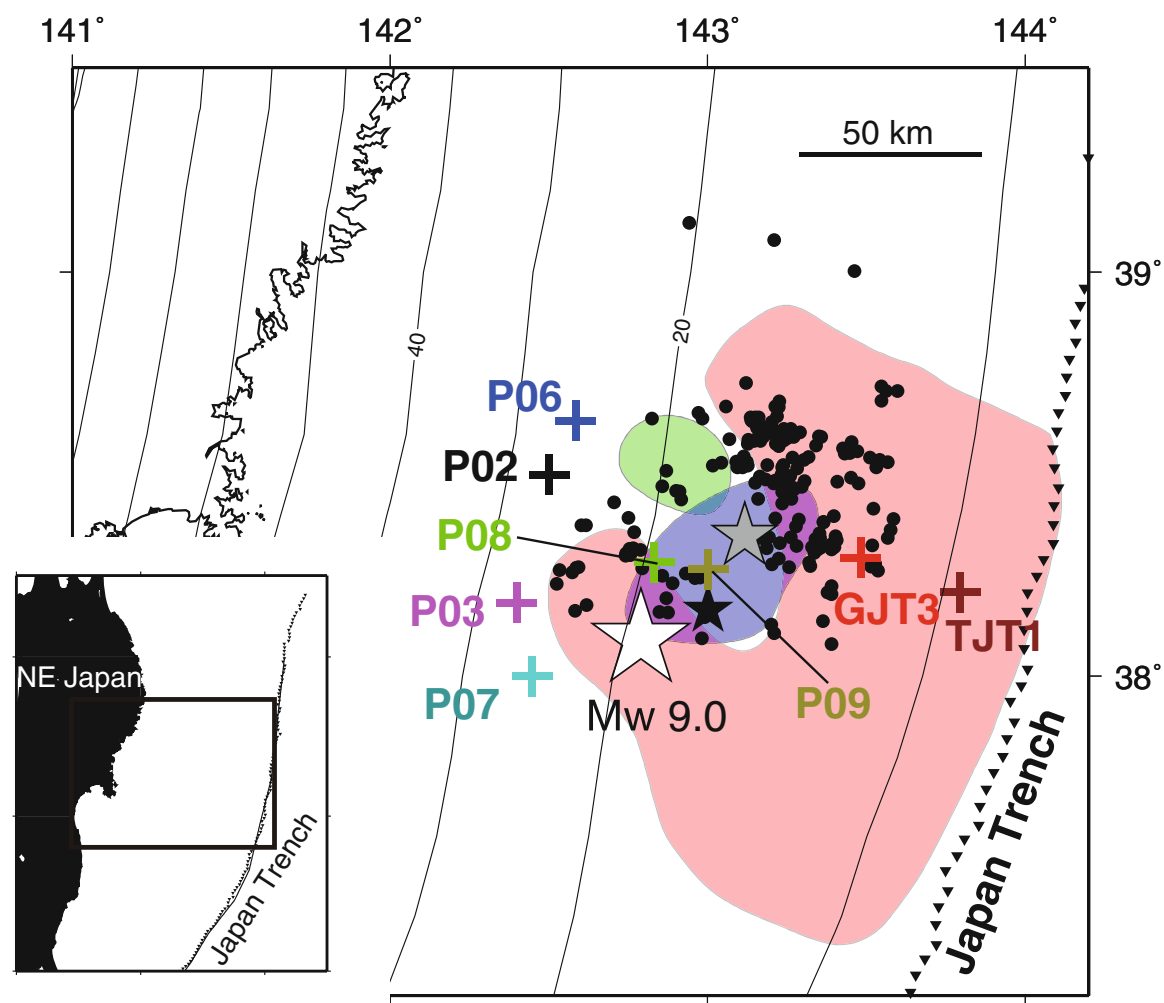


Table 1 Location and recording period of OBPRs

\begin{tabular}{llllll}
\hline Station & $\begin{array}{l}\text { Latitude } \\
\left({ }^{\circ} \mathrm{N}\right)\end{array}$ & $\begin{array}{l}\text { Longitude } \\
\left({ }^{\circ} \mathrm{E}\right)\end{array}$ & $\begin{array}{l}\text { Depth } \\
(\mathrm{m})\end{array}$ & Start $^{\mathrm{a}}$ & End $^{\mathrm{a}}$ \\
\hline P02 & 38.5002 & 142.5016 & 1,104 & $26 / 06 / 2010$ & $23 / 05 / 2011$ \\
P03 & 38.1834 & 142.3998 & 1,052 & $23 / 06 / 2010$ & $04 / 09 / 2011$ \\
P06 & 38.6340 & 142.5838 & 1,254 & $26 / 06 / 2010$ & $23 / 05 / 2011$ \\
P07 & 38.0016 & 142.4495 & 1,059 & $29 / 09 / 2010$ & $11 / 09 / 2011$ \\
P08 & 38.3829 & 142.8320 & 1,418 & $29 / 09 / 2010$ & $24 / 09 / 2011$ \\
P09 & 38.2650 & 143.0002 & 1,556 & $29 / 09 / 2010$ & $23 / 09 / 2011$ \\
GJT3 & 38.2945 & 143.4814 & 3,293 & $15 / 11 / 2010$ & $28 / 05 / 2011$ \\
TJT1 & 38.2095 & 143.7959 & 5,771 & $04 / 10 / 2010$ & $21 / 03 / 2011$ \\
\hline
\end{tabular}

a Shown in day/month/year

that an aseismic slip event began on 25 January 2011, about 40 days before the mainshock, and was accompanied by swarm-like interplate seismicity. The epicenters of the swarm showed spatial migration with a speed of 2-10 km/day (Kato et al. 2012). This observation supports acceleration of aseismic slip identified from OBPR data.

Although OBPR observations successfully detected these transient crustal deformations, we needed to examine the OBPR data more carefully to identify preseismic deformation, which could be much smaller events. To this end, we made efforts to reduce fluctuations of non-tectonic origin in the records. We used the noise levels in the processed OBPR records to estimate the sensitivity of the OBPR network for detecting slip on the plate boundary fault to constrain the range of possible preslip associated with the Tohoku-Oki earthquake.

\section{Ocean bottom pressure data}

The OBPRs that provided the data for this study use a freefall/pop-up system design and are equipped with precise quartz pressure sensors (Paroscientific Digiquartz sensors, type $8 \mathrm{~B} 7000$ ) with a scale range of $70 \mathrm{MPa}$, equivalent to the hydrostatic pressure at $7,000 \mathrm{~m}$ water depth. The oscillation frequencies of the sensor outputs were measured every $0.1 \mathrm{~s}$ (every $60 \mathrm{~s}$ for the OBPR deployed at site TJT1) and recorded with time stamps. Frequency measurement and timing were controlled by reference clocks driven by a digital temperature-compensated oscillator with a stability of $5 \times 10^{-8}$. The recorded frequency data were converted to absolute pressure by post-processing. For this study, we averaged the frequency data using a time window of $60 \mathrm{~s}$ to increase the resolution of the pressure data.

Absolute pressure data recorded on the seafloor are affected by ocean mass variations, so reliable seafloor level (SFL) estimates must compensate for those variations.
Figure 2 presents a time series of SFL data to illustrate the correction procedure explained below. Ocean tides were accounted for by harmonic analyses using the BAYTAP-G model of Tamura et al. (1991) and removed from the OBPR data (steps 1-3 in Fig. 2). The motion of the seawater layer, another major component of ocean mass variation, was estimated by using a global barotropic ocean model forced by synoptic atmospheric disturbances (Inazu et al. 2012), and its contribution was subtracted from the tide-free pressure data (steps 4 and 5 in Fig. 2). Long-term pressure recordings often suffer from instrumental drift that is characteristic of quartz pressure sensors (e.g. Watts and Kontoyiannis 1990). Here, we expressed drift as a combination of an initial exponential decreasing part and a linear component, as suggested by Watts and Kontoyiannis (1990). We fitted the drift model to each of the observed time series to estimate the drift function of individual sensors (steps 6 and 7 in Fig. 2), assuming that the pressure data do not contain any geophysical signals from the beginning of the recording (Table 1) to 20 January 2011, just before the slow slip event reported by Ito et al. (2013).

After removing these effects, the residual pressure data were converted to the SFL change at the observation site. Figure 3 shows the SFL time series in 2011 before the mainshock on 11 March. Crustal deformation prior to the mainshock is evident in the SFL records, along with coseismic and postseismic deformation associated with the two largest foreshocks. Coseismic subsidence was observed at two landward stations, P02 and P06, and uplift was observed at P09 after the largest foreshock of 9 March, followed by gradual uplift at stations P09 and GJT3 and gradual subsidence at P02 and P06. At P09, another coseismic step accompanied the second-largest foreshock.

In the period before these foreshocks, the SLF time series showed fluctuations of $<5 \mathrm{~cm}$ amplitude and various periods, although average levels were unchanged. The strong similarity among the records at different locations suggests that the SFL fluctuations were caused by some phenomenon having a spatial scale greater than $100 \mathrm{~km}$, the size of the OBPR array. Tectonic activities at such a large scale are unlikely because there were no signs of significant crustal deformations in onshore data (Hirose 2011). We interpreted these coherent fluctuations to be of nontectonic origin and regarded them as common mode noise. Under that reasoning, removing the common mode noise component can increase the signal-to-noise ratio of the SFL records and better enable us to detect small tectonic signals.

Principal component analysis (PCA) is a mathematical procedure that uses an orthogonal transformation to convert a set of observations of possibly correlated variables into a set of values of uncorrelated variables (e.g. Jollife 2002). Here, we applied PCA to extract a component that is 
Fig. 2 Processing of SFL time series obtained at site $\mathrm{P} 02$. a Time series from 1 January to 13 March 2011: 1, raw data; 2, ocean tide variation estimated by BAYTAP-G; 3 , SFL after removing the modeled ocean tide (amplified 10 times); 4, nontidal fluctuation predicted by global ocean modeling (amplified 10 times); and 5, SFL corrected for both tidal and nontidal variations (amplified 10 times). b Time series from 1 July 2010 to 13 March 2011, showing long-term variation of SFL data. 5:SFL corrected for both tidal and nontidal variations (same as in a), 6: curve expressing estimated instrumental drift, 7: SFL data after removing the drift component

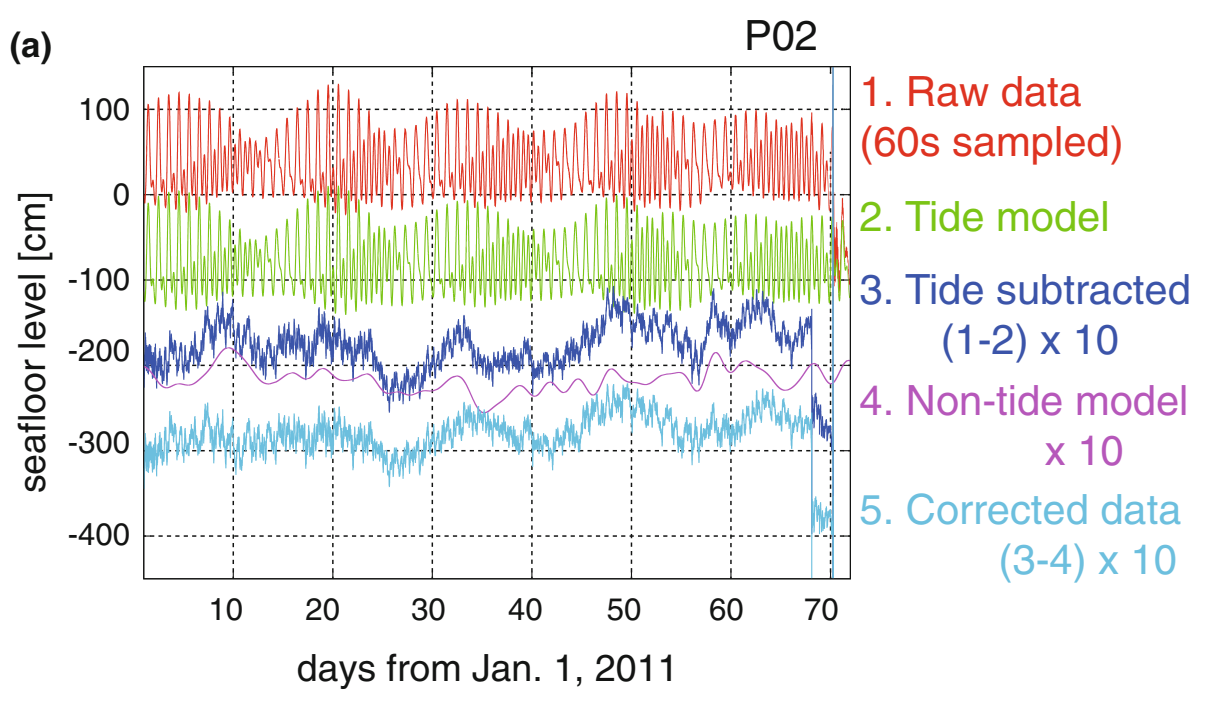

(b)

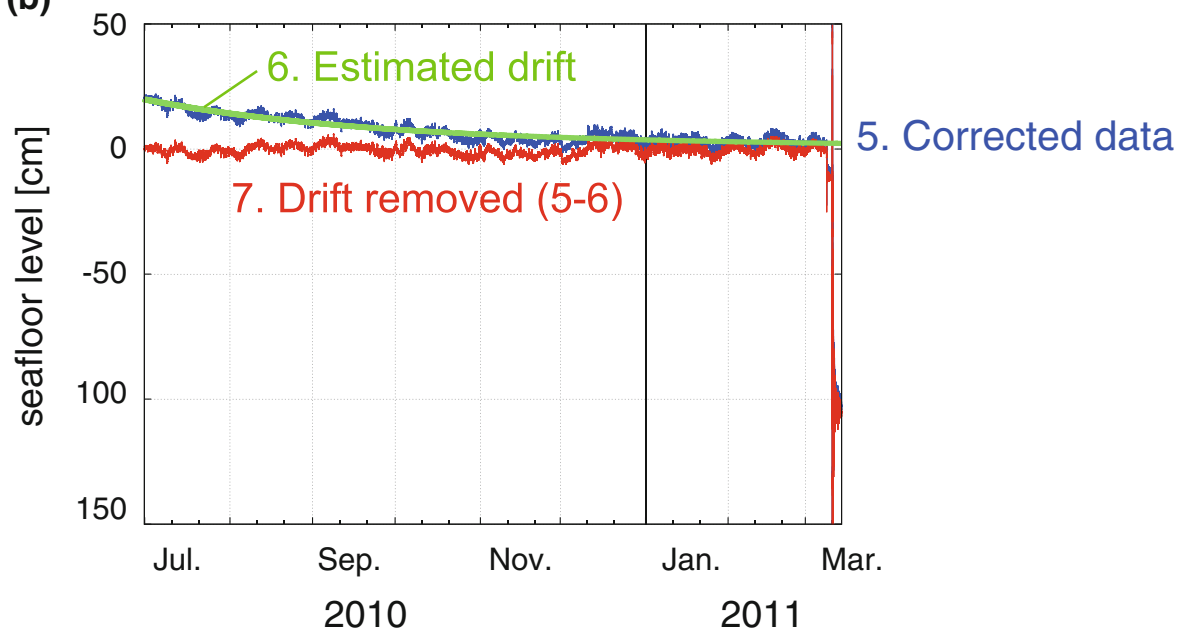

common to all of the SFL records and uncorrelated with the remaining components. Given the strong similarity among the SFL data, we expected that the first principal component (1st PC) is representative of the common mode noise and that subtracting the 1st PC from the SFL time series would effectively reduce the common mode noise. For that reason we refer to the process as common mode noise reduction (CMNR) hereafter.

Before applying PCA to the SFL data, we removed the coseismic steps, as estimated by a least-squares method by Ohta et al. (2012), from the two major foreshocks (Fig. 2). Then we applied PCA to the preprocessed SFL time series from 1 January to 11 March 2011 to PCA and estimated the 1st PC, which in turn was removed from the SFL data (Fig. 3). The resulting time series shows that after CMNR the coherent fluctuations are considerably reduced and also that the traces are less correlated with one another (Table 2). The SFL time series observed at TJT1 shows long-period ( $\sim 10$ days) fluctuations even after subtracting the 1st PC. The largest excursion started around 45 days after 1 January, when the seafloor at TJT1 subsided by $\sim 4 \mathrm{~cm}$. The timing of this movement corresponds well to that of the crustal deformation reported by Ito et al. (2013).

\section{Precursory deformation prior to the Tohoku-Oki earthquake}

The noise levels before and after CMNR, defined as three times the standard deviation $(3 \sigma)$ of the SFL fluctuation (Polster et al. 2009), are listed in Table 2 for each OBPR station. After applying CMNR, changes in SFL of more than $\sim 2 \mathrm{~cm}$ can be recognized as significant signals. Figure 4 shows the SFL data after CMNR for the 11 days before the Tohoku-Oki earthquake. Gradual uplift or subsidence caused by postseismic deformation after the Mw 7.3 foreshock are clearly identified in the records of stations P09, GJT3, P03, P02, and P06 in Fig. 4a. The amount of equivalent seismic moment released by the afterslip was 


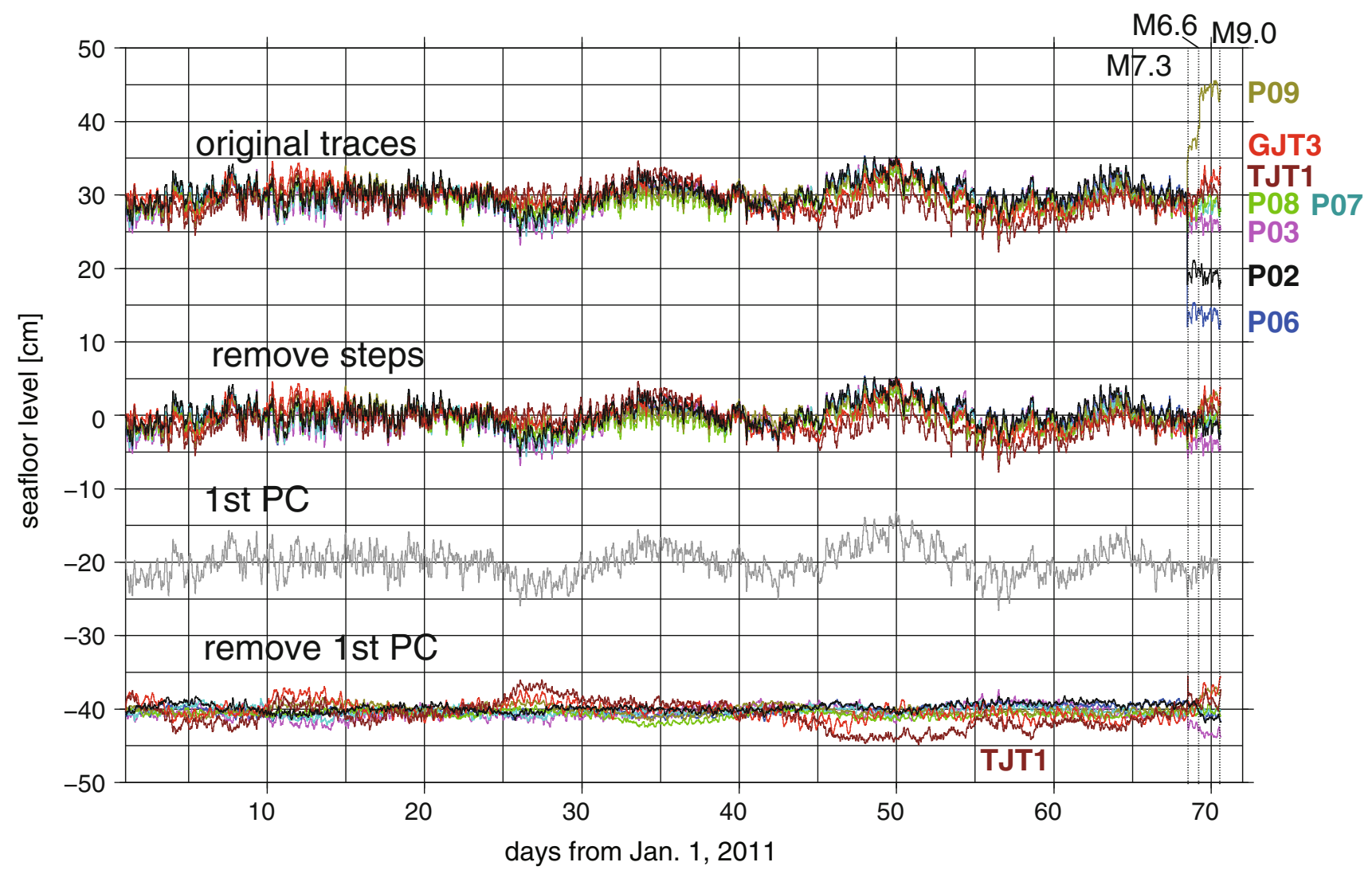

Fig. 3 Time series of SFL variation derived from ocean bottom pressure records from 1 January 2011 to the origin time of the Tohoku-Oki earthquake mainshock on 11 March. The top group of traces is SFLs after removing ocean tides and nontidal fluctuation

Table 2 Noise level and cross-correlation coefficient of SFL records

\begin{tabular}{llllll}
\hline Station & \multicolumn{2}{l}{ Without CMNR } & & With CMNR \\
\cline { 2 - 3 } \cline { 6 - 6 } \cline { 6 - 6 } & Noise level $(\mathrm{cm})$ & x-cor $^{\mathrm{n}}$ & & Noise level $(\mathrm{cm})$ & x-cor $^{\mathrm{a}}$ \\
\hline P02 & 4.5 & 0.75 & & 1.8 & 0.44 \\
P03 & 4.7 & 0.58 & 2.4 & 0.41 \\
P06 & 4.4 & 0.78 & 1.5 & 0.28 \\
P07 & 4.7 & 0.66 & 2.1 & 0.41 \\
P08 & 4.2 & 0.87 & 1.2 & 0.19 \\
P09 & 3.1 & 1.00 & 2.0 & 1.00 \\
GJT3 & 4.7 & 0.82 & 3.6 & 0.57 \\
TJT1 & 4.8 & 0.75 & 3.6 & 0.36 \\
\hline
\end{tabular}

${ }^{a}$ Cross-correlation coefficient with respect to the SFL at P09

estimated as $\mathrm{Mw} \sim 6.8$ from the postseismic deformation data (Ohta et al., 2012). To isolate the postseismic deformation from the SFL data, we fitted the logarithmic function $f(x)=a \log (1+t / \tau)$ to the observed time series, where $t$ is the elapsed time since the Mw 7.3 foreshock, $\tau$ is the decay time constant, and $a$ is the magnification predicted by the global ocean model. The second group is SFL traces after removing coseismic steps. The trace in the third row is the first principal component (1st PC). The bottom group is SFL traces after subtracting the 1 st PC

factor. In this study, we adopted a value of $\tau$ of 0.2 days according to the estimation by Ohta et al. (2012). Figure $4 \mathrm{~b}$ shows the SFL after removing the postseismic deformation.

Beyond this postseismic deformation, it was difficult to identify statistically significant changes in the SFL data prior to the mainshock (Fig. 4b). Figure 5 shows a detail of the adjusted SFL data, which we inspected for notable changes. At TJT1, the easternmost station (Fig. 1), a slight increase of the uplift rate may have occurred approximately $4 \mathrm{~h}$ before the mainshock, although the SFL change was $\sim 3 \mathrm{~cm}$, almost equivalent to the noise level. To further assess this event, we prepared histograms of the background rates of vertical seafloor deformation over 4-h sliding/overlapping windows in the SFL data before 20 January (Fig. 6). The deformation rates in the last 4-h period before the mainshock are within the distribution of these fluctuations for all the stations, including TJT1. Although the displacement at TJT1 was in the top $0.4 \%$ of observed 4-h changes, it is difficult to argue for the existence of precursory events to the Tohoku-Oki earthquake. 


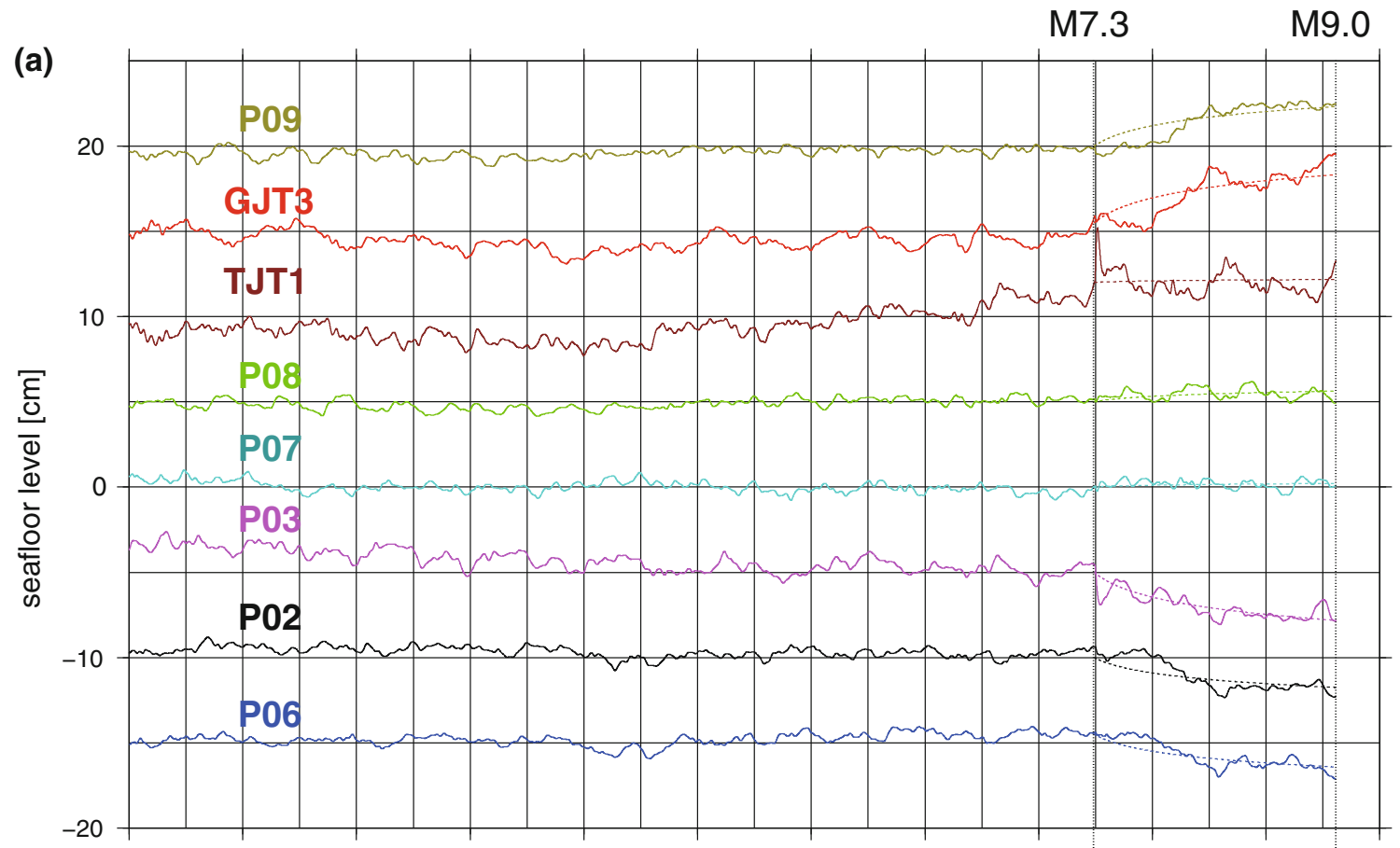

(b)

20
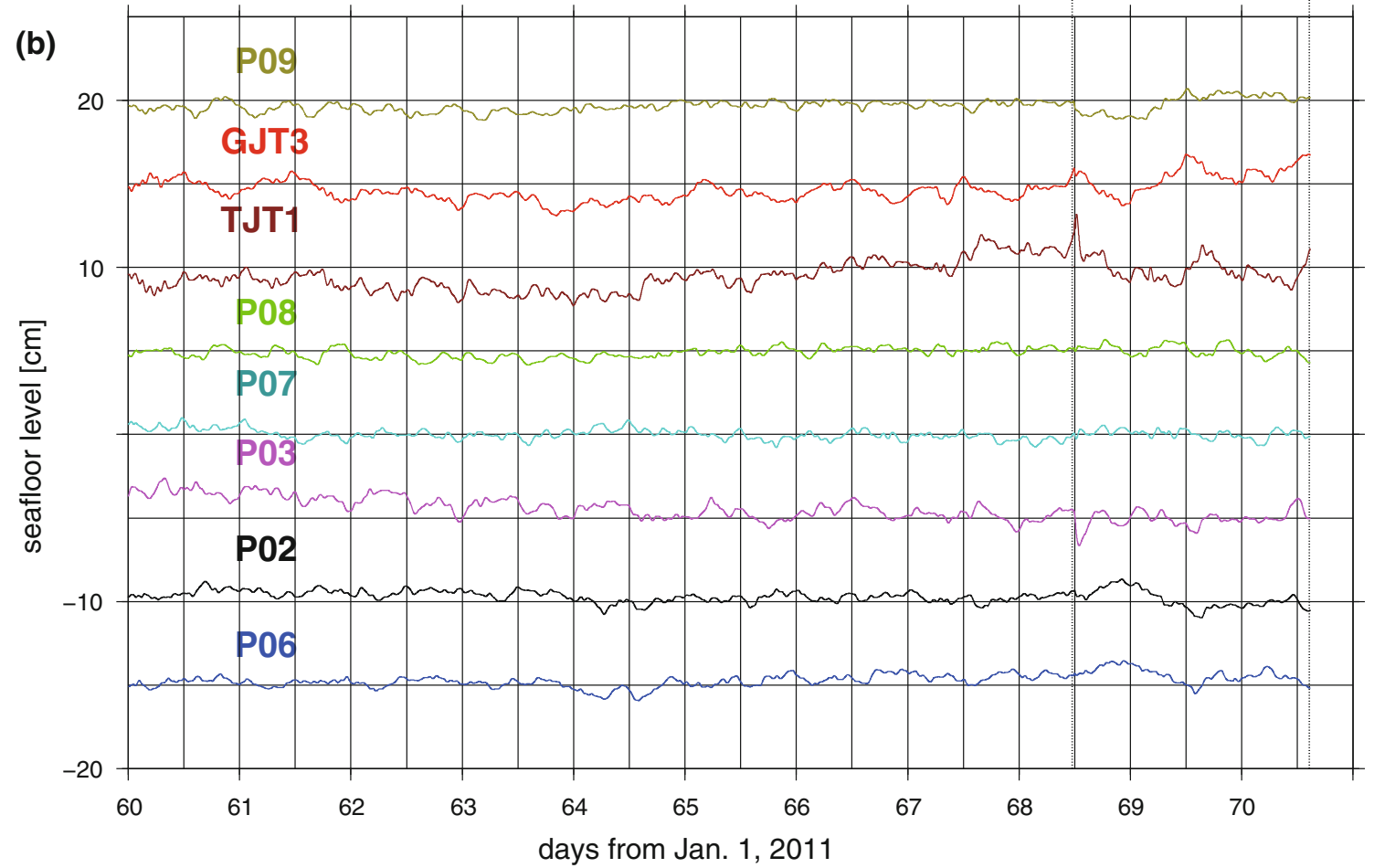

Fig. 4 Time series of SFL variation for the 11 days before the mainshock after applying CMNR. a SFL after CMNR. Dashed lines show temporal variation due to post-foreshock (Mw 7.3) deformation,

\section{Sensitivity of the OBPR array to slip on the plate interface}

Although we could not find evidence of significant preseismic crustal deformation, it is also important for studies of the Tohoku-Oki earthquake to determine how effective obtained by log- $t$ fitting to the observations. b SFL time series after subtracting the log-t postseismic deformation

OBPR arrays are in detecting preslip events. Therefore, we calculated the smallest amount of slip on the plate boundary that could be detected by at least one of the OBPRs. The thresholds of event detection by the OBPRs were assumed to be the noise levels in the SFL records after CMNR processing (Table 2). We distributed double- 


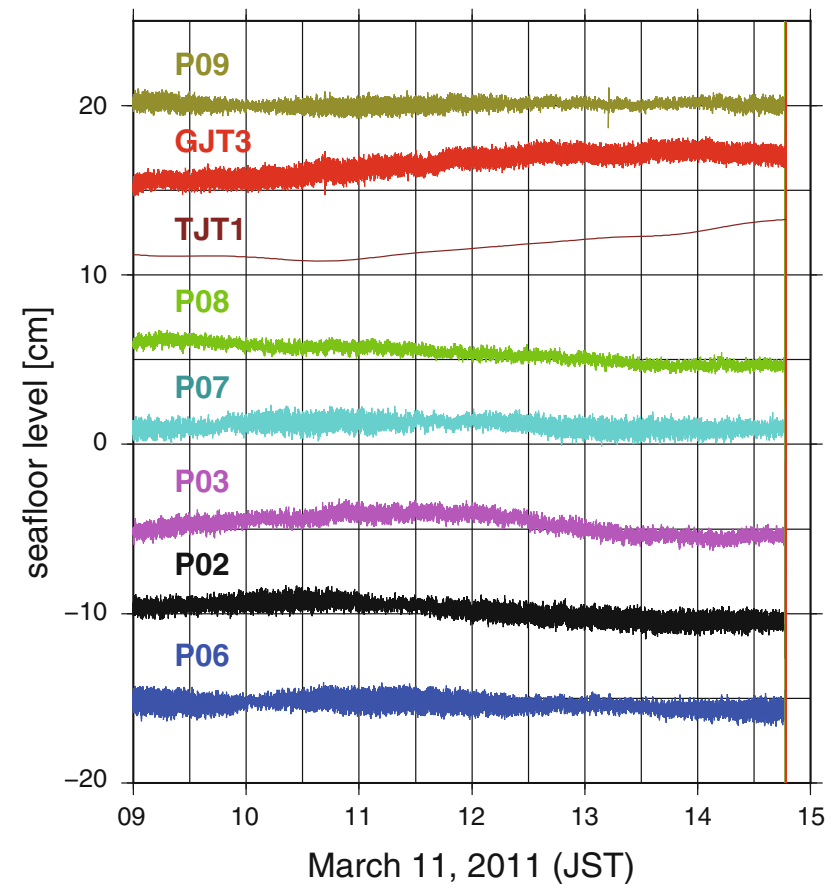

Fig. 5 Time series of SFL variation for $\sim 6 \mathrm{~h}$ before the mainshock. Common mode noise and the postseismic deformation are removed. Sampling intervals is $1 \mathrm{~s}$ for all data, except those from TJT1, where the sampling interval is $60 \mathrm{~s}$ couple point sources along the plate boundary with $0.05^{\circ}$ spacing and determined the minimum detectable event size at every location. For each point source, we assumed reverse faulting with the slip direction opposite to the subduction direction of the Pacific plate (Apel et al. 2006). The resulting vertical displacements at the OBPR stations were calculated by Okada's (1992) analytical expression for a point source in an elastic half-space. The geometry of the subducting Pacific slab was adopted from the model of Nakajima et al. (2009), slightly modified beneath the offshore area after the marine seismic survey of Ito et al. (2005). Slip event sizes were converted to equivalent $\mathrm{Mw}$ assuming a rigidity of $30 \mathrm{GPa}$.

Figure 7 shows the distribution of the minimum size of slip event detectable by the OBPR array. As expected, the OBPR records are most sensitive to fault slip directly beneath the observatories. OBPR sensitivity largely depends on the distance from the OBPR station, the noise level of the SFL data, and the depth to the plate boundary. The detectable size is smallest, $\mathrm{Mw} \sim 5.9$, beneath the array center. Near the epicenter of the Tohoku-Oki earthquake, one of the most probable locations for preslip, the detectable size is $\mathrm{Mw} \sim 6.2$. In other words, precursory vertical deformation greater than the equivalent of an Mw 6.2 event would have
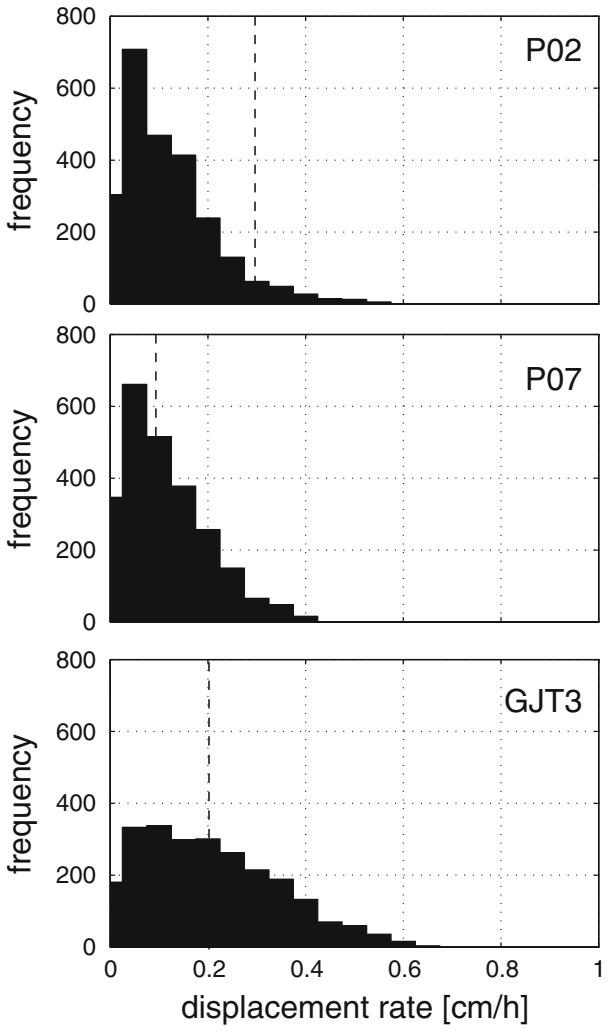

Fig. 6 Histograms showing the distribution of rates of vertical displacement in 4-h periods for the eight OBPRs. Rates are calculated for the CMNR-processed SFL records before 20 January, a period
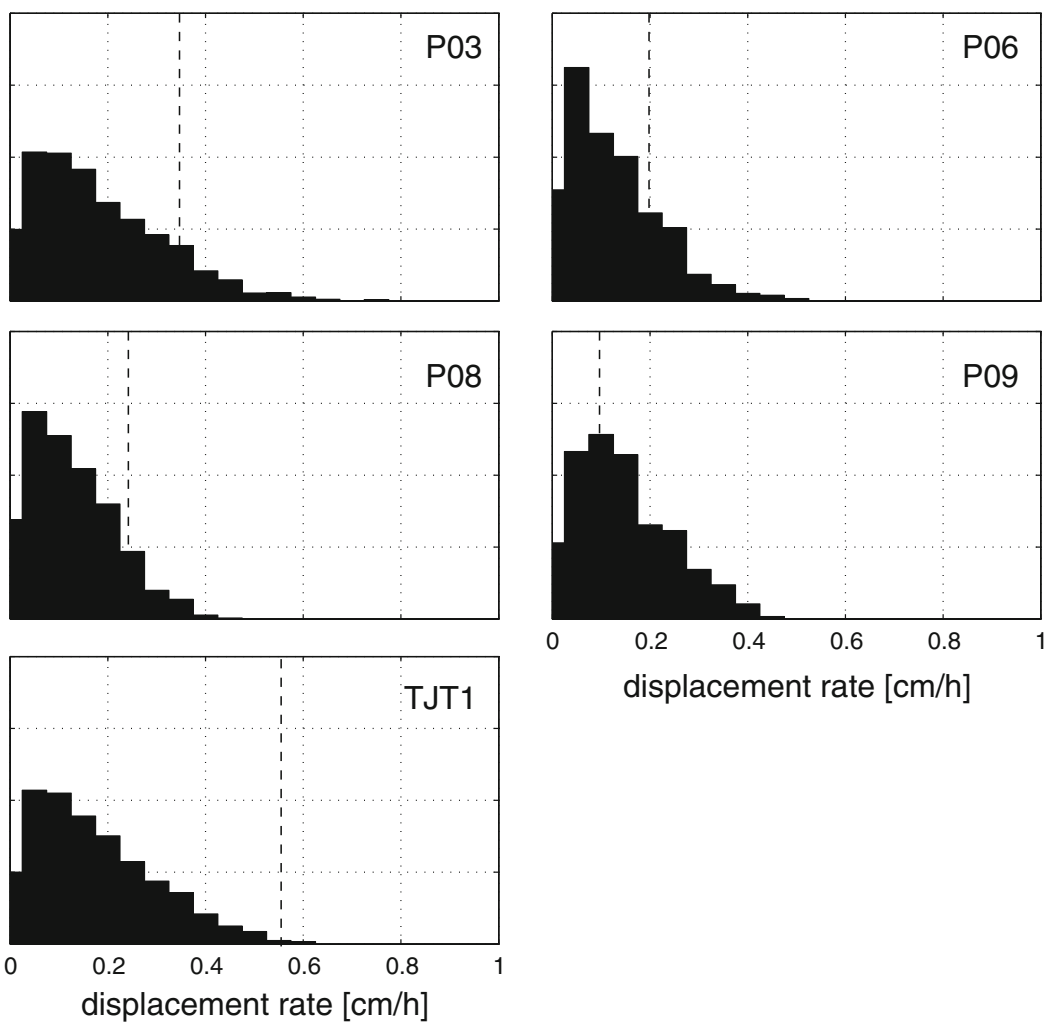

displacement rate $[\mathrm{cm} / \mathrm{h}]$ without noticeable crustal deformation events. Dotted lines show the rates of vertical displacement for the 4-h period just before the mainshock 

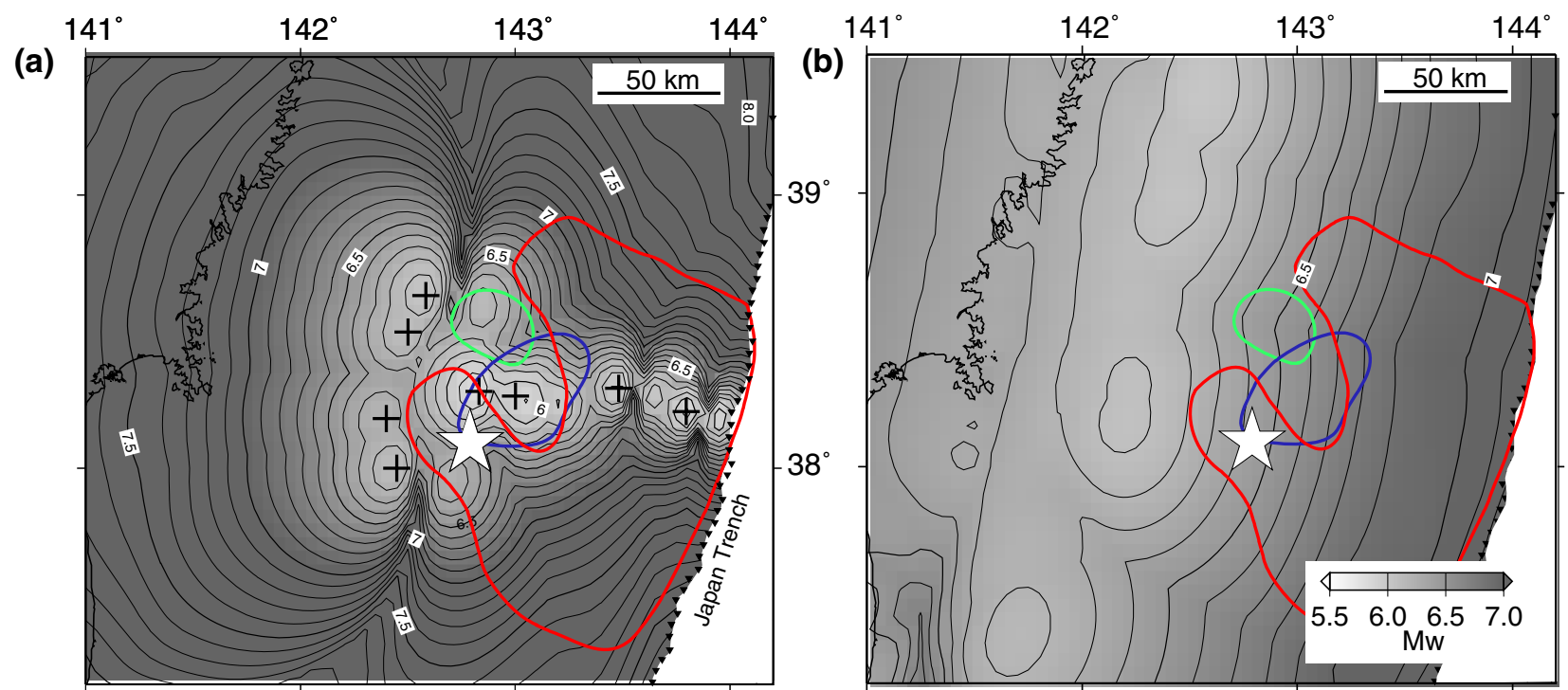

$39^{\circ}$

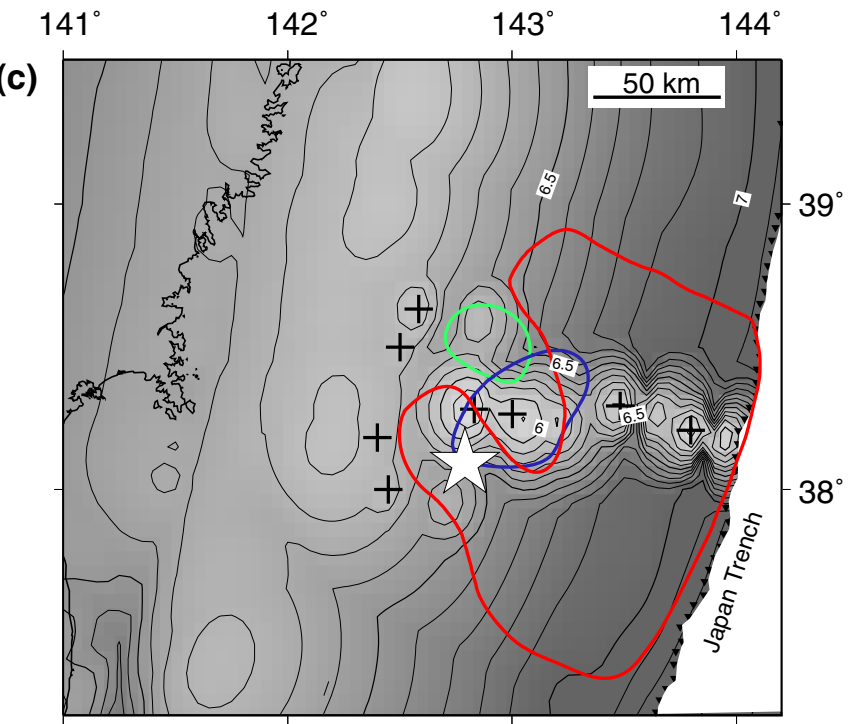

Fig. 7 Maps showing sensitivities of local geodetic observations to interplate slip events on the subducting Pacific plate. The minimum size of slip event identifiable in the CMNR-processed SFL or cGPS records is shown by gray scale and contours of moment release expressed as Mw (0.1 interval). Red, green, and blue lines enclose the

been detected by our OBPR observations. Preslip exceeding $\mathrm{Mw} \sim 6.0$ at shallow depths near the trench could have been detected by the easternmost OBPR station TJT1. The SFL change at TJT1 prior to the mainshock, which was within the noise level, could have been caused by preslip of $\mathrm{Mw}<6$ at the updip end of the megathrust, although we cannot recognize it as a significant signal.

\section{Discussion}

Hirose (2011) examined onshore tilt records from before the Tohoku-Oki earthquake and concluded that they area of $>30 \mathrm{~m}$ coseismic slip in the mainshock, $>1 \mathrm{~m}$ coseismic slip in the largest foreshock, and $>0.3 \mathrm{~m}$ afterslip following the largest foreshock, respectively (see Fig. 1). a Sensitivity of OBPR data, b Sensitivity of cGPS data. c Sensitivity using both OBPR and cGPS data

provided no clear evidence of preseismic crustal deformation events larger than $\mathrm{Mw} 7.3$ near the epicenter or larger than $\mathrm{Mw} 6.2$ on the deeper extension of the mainshock rupture area. We estimated the distribution of the minimum size of slip events along the plate boundary fro which surface displacement could be identified in terrestrial cGPS observations (Fig. 7b). The procedure is similar to that for deriving the detectability map of the OBPR array. We assumed that the noise level of cGPS data is $\sim 0.8 \mathrm{~cm}$ in horizontal displacement from inspection of the quality of actual cGPS data obtained in the Pacific coastal area. Dense terrestrial cGPS network can detect slip events larger than $\mathrm{Mw} \sim 6.5$ near the hypocenter and events larger 
than $\mathrm{Mw} \sim 6.2$ on the deeper, more landward part of the fault. Our study demonstrates that OBPR data substantially improve the detectability of slip beneath the shallow offshore part of the plate boundary, whereas onshore data are more sensitive to slip in the deeper part. Combining onshore and offshore observations, we conclude that the Tohoku-Oki earthquake was not preceded by precursory slip larger than $\mathrm{Mw} \sim 6.2$ around the hypocenter and at the deeper extension of the rupture zone (Fig. 7c).

One of the possible mechanisms of preslip is rupture nucleation. Although there is no agreement on what relation the seismic nucleation phase has to the eventual earthquake size, Yoshida and Kato (2005) estimated that the size difference between the nucleation and the final rupture can be 2.0-2.6 magnitude units based on several assumptions. As preslip associated with nucleation is expected to occur where the seismic rupture starts, preslip of this type should occur near the hypocenter. For typical megathrust earthquakes of $\mathrm{Mw} \sim 8$, preslips should be equivalent to events of $\mathrm{Mw}$ $5.5-6$, and they would be difficult to detect by terrestrial geodetic observations because their hypocenters are usually far offshore. If the scaling relation between aseismic slip associated with nucleation and the eventual seismic rupture holds for the Tohoku-Oki earthquake (Mw 9.0), its preslip size would be Mw 6.4-7.0, above the detection threshold for OBPR observations. We could not identify evidence of such preslip before the Tohoku-Oki earthquake; thus, our observations indicate that any precursory aseismic slip was much smaller than the size predicted by previous studies.

Chu et al. (2011) reported that the Tohoku-Oki earthquake began as a small (Mw 4.9) thrust event by analyzing the early teleseismic body waves from the mainshock. Their result suggests that the rupture initiation of the Tohoku-Oki earthquake can be explained by a cascade model (e.g. Ellsworth and Beroza 1995), in which seismic slip initiates on a small fault patch and continues to rupture further across a fault plane. The absence of detectable preslip near the hypocenter is consistent with this concept, although the observational evidence is scant. Noda et al. (2013) showed considerable variation in the growth process of large earthquakes in a hierarchical asperity model, in which a large strong fault patch and smaller patches were irregularly distributed. A large earthquake is triggered by dynamic cascade of a small earthquake, but the same large fault patch may occasionally break after substantially large quasi-static nucleation.

Extensive efforts are being made in Japan to build cabled seafloor systems for earthquake and tsunami monitoring (Monastersky 2012; Kaneda 2012). Such systems use seafloor pressure gauges for tsunami observation. This study demonstrates how seafloor pressure monitoring may also improve the detection of slip on the plate boundary fault beneath offshore areas. Along the Nankai Trough, where extraordinarily large earthquakes $(\mathrm{Mw} \gg 8)$ are anticipated, the plate boundary is shallower than in the hypocentral area of the Tohoku-Oki earthquake. Our results therefore suggest that seafloor pressure observations in the Nankai Trough can sense slow-slip events of $\mathrm{Mw}$ $\sim 6$. Although the OBPR data from the epicentral region of the Tohoku-Oki earthquake showed no substantial preslip, it is clear that slow slip at the shallow plate boundary in early 2011 (Ito et al. 2013) and postseismic slip after the large foreshock (Ohta et al. 2012) played important roles in the generation of the mainshock. Therefore, real-time monitoring of slip by combining terrestrial and seafloor observations appears promising for evaluating the imminence of large interplate earthquakes.

Our calculations showed that reducing the noise in the SFL data by using CMNR increases the OBPR network's sensitivity to slip events on the plate boundary by about 0.2 magnitude unit (Table 2). This indicates the importance of noise reduction for isolating nontectonic irregularities. Fluctuations in bottom pressure records caused by ocean mass variations may differ from one region to another, and their character may have to be clarified through investigation of field data. Statistical treatments of seafloor pressure data, as tested in this study, may succeed in enhancing the sensitivity of SFL data by identifying variations of nontectonic origin.

\section{Conclusion}

We examined continuous seafloor vertical deformation data obtained by ocean-bottom pressure observations around the epicenter of the 11 March 2011 Tohoku-Oki earthquake to search for precursory crustal deformation. After removing ocean-tide variations and nontidal fluctuations predicted by a global ocean model, the SFL records still contained noise originating from nontectonic processes. Taking advantage of the strong similarity of the noise among the different observing stations, we used PCA to identify and remove part of this noise component from the records. The resulting SFL data enabled us to detect deformations of $2-4 \mathrm{~cm}$. This time series showed no significant preseismic crustal deformation other than gradual deformation due to afterslip of the Mw 7.3 foreshock of 9 March. We confirmed that ocean-bottom observations are more sensitive detectors of aseismic slip on the plate boundary than terrestrial geodetic observations. Although our results did not exclude the possibility of preslip, they suggest that the size of any slip was no larger than the equivalent of a Mw 6.2 event, if it occurred near the hypocenter associated with the rupture nucleation process, and no larger than Mw 6.0 if it occurred near the trench. 
Acknowledgments Deployment and retrieval of OBPRs were conducted by R/V Ryofu-maru and R/V Keifu-maru of Japan Meteorological Agency, R/V Kairei and R/V Natsushima of Japan Agency for Marine-Earth Science and Technology, and R/V Hakuho-maru and R/V Tansei-maru of the University of Tokyo. We thank the captains and crews of these vessels for their assistance. Thoughtful comments by Roland Bürgmann and an anonymous reviewer were helpful in improving this manuscript. This study was supported by the research project "Research concerning Interaction between the Tokai, Tonankai and Nankai Earthquakes" of the Ministry of Education, Culture, Sports, Science and Technology, and by Grant-in-Aid for Scientific Research (A) 20244070 from the Japan Society for the Promotion of Science. The Generic Mapping Tools (Wessel and Smith 1998) were used for creating the figures.

Open Access This article is distributed under the terms of the Creative Commons Attribution License which permits any use, distribution, and reproduction in any medium, provided the original author(s) and the source are credited.

\section{References}

Apel EV, Bürgmann R, Steblov G, Vasilenko N, King R, Prytkov A (2006) Independent active microplate tectonics of northeast Asia from GPS velocities and block modelling. Geophys Res Lett 33. doi:10.1029/2006GL026077

Chu R, Wei S, Helmberger DV, Zhan Z, Zhu L, Kanamori H (2011) Initiation of the great $M w 9.0$ Tohoku-Oki earthquake. Earth Planet Sci Lett 308:277-283

Ellsworth WL, Beroza CG (1995) Seismic evidence for an earthquake nucleation phase. Science 268:851-855

Hirose H (2011) Tilt records prior to the 2011 off the Pacific coast of Tohoku Earthquake. Earth Planets Place 63:655-658

Iinuma T, Hino R, Kido M, Inazu D, Osada Y, Ito Y, Ohzono M, Tsushima H, Suzuki S, Fujimoto H, Miura S (2012) Coseismic slip distribution of the 2011 off the Pacific Coast of Tohoku Earthquake (M9.0) refined by means of seafloor geodetic data. J Geophys Res 117:B07409. doi:10.1029/2012JB009186

Inazu D, Hino R, Fujimoto H (2012) A global barotropic ocean model driven by synoptic atmospheric disturbances for detecting seafloor vertical displacements from in situ ocean bottom pressure measurements. Mar Geophys Res. doi:10.1007/s11001-012-9151-7

Ito A, Fujie G, Miura S, Kodaira S, Kaneda Y (2005) Bending of the subducting oceanic plate and its implication for rupture propagation of large interplate earthquakes off Miyagi, Japan, in the Japan Trench subduction zone. Geophys Res Lett 32: doi:10. 1029/2004GL022307

Ito Y, Tsuji T, Osada Y, Kido M, Inazu D, Hayashi Y, Tsushima H,Hino R, Fujimoto H (2011) Frontal wedge deformation near the source region of the 2011 Tohoku Oki earthquake. Geophys Res Lett 38: doi:10.1029/2011GL04835

Ito Y, Hino R, Kido M, Fujimoto H, Osada Y, Inazu D, Ohta Y, Iinuma T, Ohzono M, Miura S, Mishina M, Suzuki K, Tsuji T, Ashi J (2013) Episodic slow slip events in the Japan subduction zone before the 2011 Tohoku-Oki earthquake. Tectonophysics (in press)

Jollife IT (2002) Principal component analysis, 2nd edn. Springer, New York

Kaneda Y (2012) Real-time monitoring on the megathrust seismogenic zones around the Nankai trough, southwestern JapanDONET and DONET2 development and data application. Abstract 2012 AGU Fall Meeting OS52A-02
Kato A, Obara K, Igarashi T, Tsuruoka H, Nakagawa S, Hirata N (2012) Propagation of slow slip leading up to the $2011 \mathrm{Mw} 9.0$ Tohoku-Oki Earthquake. Science 335:705-708

Kido M, Osada Y, Fujimoto H, Hino R, Ito Y (2011) Trench-normal variation in observed seafloor displacements associated with the 2011 Tohoku-Oki earthquake. Geophys Res Lett 38: doi:10. 1029/2011GL050057

Linde AT, Sacks IS (2002) Slow earthquakes and great earthquakes along the Nankai trough. Earth Planet Sci Lett 203:265-275

Melbourne TI, Webb FH (2002) Precursory transient slip during the $2001 \mathrm{Mw}=8.4$ Peru earthquake sequence from continuous GPS. Geophys Res Lett 29: doi:10.1029/2002GL015533

Monastersky R (2012) The next wave. Nature 483:144-146

Nakajima J, Tsuji Y, Hasegawa A (2009) Seismic evidence for thermally-controlled dehydration in subducting oceanic crust. Geophys Res Lett 36: doi:10.1029/2008GL036865

Nishimura T (2012) Crustal deformation of northeastern Japan based on geodetic data for recent 120 years. J Geol Soc Jpn 118:278-293 (in Japanese with English abstract)

Noda H, Nakatani M, Hori T (2013) Large nucleation before large earthquake is sometimes skipped due to cascade-up-Implications from rate- and state- simulation of faults with hierarchical asperities. J Geophys Res (in press)

Ohta Y, Hino R, Inazu D, Ohzono M, Ito Y, Mishina M, Iinuma T, Nakajima J, Osada Y, Suzuki K, Fujimoto H, Tachibana K, Demachi T, Miura S (2012) Geodetic constraints on afterslip characteristics following the March 9, 2011, Sanriku-oki earthquake, Japan. Geophys Res Lett 39: doi:10:1029/2012GL052430

Okada Y (1992) Internal deformation due to shear and tensile faults in a halfspace. Bull Seismol Soc Am 82:1018-1040

Ozawa S, Nishimura T, Munekane H, Suito H, Kobayashi T, Tobita M, Imakiire T (2012) Preceding, coseismic and postseismic slips of the 2011 Tohoku earthquake, Japan. J Geophys Res 117: doi: 10.1029/2011JB009120

Polster A, Fabian M, Villinger H (2009) Effective resolution and drift of Paroscientific pressure sensors derived from long-term seafloor measurements. Geochemistry, Geophysics, Geosystems 10: doi:10.1029/2009GC002532

Roeloffs EA (2006) Evidence for aseismic deformation rate changes prior to earthquakes. Annu Rev Earth Planet Sci 34:591-627

Sato M, Ishikawa T, Ujihara N, Yoshida S, Fujita M, Mochizuki M (2011) Displacement above the hypocenter of the 2011 TohokuOki earthquake. Science 332:1395. doi:10.1126/science.1207401

Scholz C (2002) The mechanics of earthquakes and faulting, 2nd edn. Cambridge Univ Press, Cambridge

Suzuki K, Hino R, Ito Y, Yamamoto Y, Suzuki S, Fujimoto H, Shinohara M, Abe M, Kawahara Y, Hasegawa Y, Kaneda Y (2012) Seismicity near the hypocenter of the 2011 off the Pacific coast of Tohoku earthquake deduced by using ocean bottom seismographic data. Earth Planets Space 64:1125-1135

Tamura Y, Sato T, Ooe M, Ishiguro M (1991) A procedure for tidal analysis with a Bayesian information criterion. Geophys J Int 104:507-516. doi:10.1111/j.1365-246X.1991.tb05697.x

Watts DR, Kontoyiannis H (1990) Deep-ocean bottom pressure measurements: drift removal and performance. J Atmos Oceanic Technol 7:296-306

Wessel P, Smith WHF (1998) New, improved version of the Generic Mapping Tools released. Eos Trans AGU 79:579

Yoshida S, Kato N (2005) Dependence of preslip on eventual earthquake size. Zisin, 2nd ser. J Seismol Soc Jpn 58:231-246 (in Japanese with English abstract) 